\title{
Posicionamiento Web \\ y Medios de Comunicación Ciclo de Vida de una Campaña y Factores SEO
}

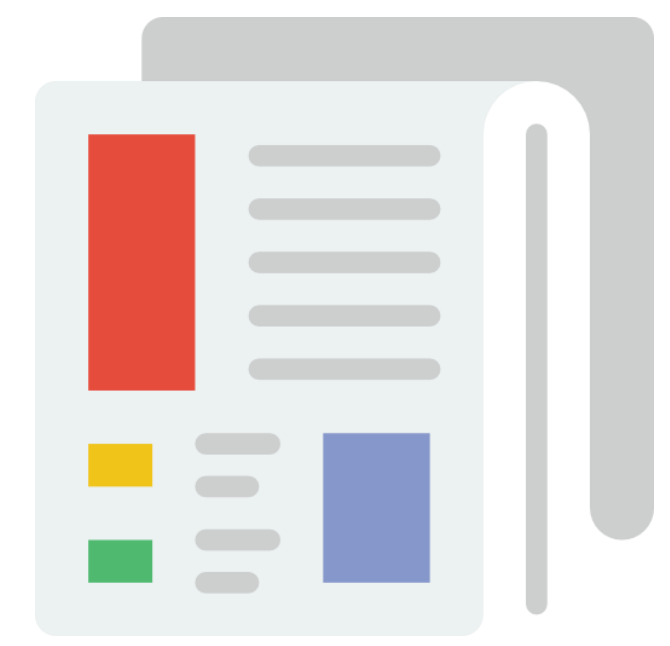

\author{
Lluís Codina, Carlos Gonzalo-Penela, \\ Rafael Pedraza-Jiménez, Cristòfol Rovira
} (UPF)

Una publicación del Grupo de Investigación DigiDoc Febrero 2017 


\section{Grupo de Investigación DigiDoc}

UPF

Roc Boronat, 138, desp. 53.802

08018 Barcelona

www.upf.edu/digidoc/

Contacto: teléfono +34 935421212 | rafael.pedraza@upf.edu

CC Lluís Codina, Carlos Gonzalo-Penela, Rafael Pedraza-Jiménez, Cristòfol Rovira

Febrero 2017

Obra distribuida bajo una licencia CC BY-NC-SA 4.0

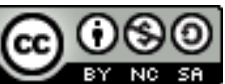

\section{Forma recomendada de citación}

\section{Lluís Codina, Carlos Gonzalo-Penela, Rafael Pedraza-Jiménez, Cristòfol Rovira.}

Posicionamiento Web y Medios de Comunicación: Ciclo de Vida de una Campaña y Factores SEO. Barcelona: Departamento de Comunicación. Serie Editorial DigiDoc, 2017

Imagen de la cubierta: Icon made by Madebyoliver in Interface from www.flaticon.com

\section{Serie Editorial DigiDoc}

Un Entregable de la Colección Proyecto Comunicación Interactiva (PCI).

Con el soporte de los proyectos: "Creación y contenido interactivo en la comunicación de información audiovisual: audiencias, diseño, sistemas y formatos. CSO2015-64955-C4-2-R. I

"El turista en la Web: hábitos informacionales y selección de destino turístico. ITOURIST" (CSO2014-59896-P)

MINECO/FEDER, Ministerio de Economía y Competitividad (España) Plan Nacional de I+D+l". NS PCI06/2017

Una producción de

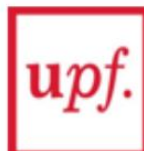

Universitat Pompeu Fabra Barcelona
Con el soporte de

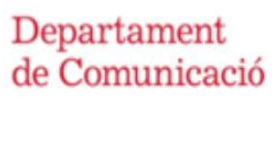

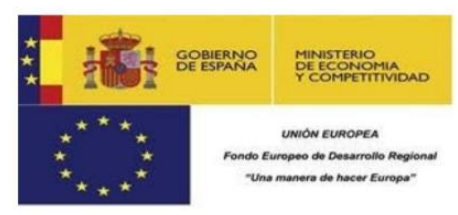




\section{Sobre los autores}

Lluís Codina es profesor de Documentación Periodística y Audiovisual en la Facultad de Comunicación de la UPF. Coordina el Seminario de Investigación del Grupo DigiDoc y forma parte del equipo de dirección, como segundo IP, del proyecto de investigación del Plan Nacional de I+D+l sobre Comunicación Interactiva dentro del que se inscribe este entregable. Es coordinador del Máster Universitario en Comunicaciòn Social (MUCS) de la UPF. Su página personal: www.lluiscodina.com. Contacto: lluis.codina@upf.edu

Carlos Gonzalo-Penela es profesor e investigador en SEO y Marketing Computacional en la Universitat Pompeu Fabra. Es director del curso de posgrado en SEO y Social Media para Comunicadores de la UPF Barcelona School of Management. Es miembro del Grupo de investigación DigiDoc. Consultor en SEM y SEO, e-comunicación, Marketing web y Web Analytics. Una de sus líneas de investigación se centra en la e-politics y en el efecto de las redes sociales y los buscadores en la formación de la opinión pública. Su página personal: www.carlosgonzalo.es. Contacto: carlos.gonzalo@upf.edu

Rafael Pedraza es profesor e investigador en documentación periodística y en desarrollo web para instituciones y proyectos culturales. Es coordinador del Grupo de Investigación DigiDoc. Está especializado, entre otras líneas, en el desarrollo de sistemas de análisis de plataformas digitales y sitios web. También lleva a cabo investigaciones sobre museos en la web, marcas de ciudades turísticas en Internet y la Web semántica. Contacto: rafael.pedraza@upf.edu

Cristòfol Rovira es profesor e investigador en Documentación Periodística y en Marketing en buscadores de la Facultad de Comunicación de la UPF. Es miembro del Grupo de Investigación DigiDoc. Es director del Máster Universitario Online en Documentación Digital y del Máster Universitario Online en Buscadores: Marketing Online, Posicionamiento, Community Manager y Content Curator ambos de la UPF Barcelona School of Management. Su página personal: cristofolrovira.com . Contacto: cristofol.rovira@upf.edu 


\section{Resumen}

Presentación de los rasgos diferenciales del SEO aplicado a los medios de comunicación, considerando, entre otros aspectos, el hecho de ser sitios intensivos en contenidos y de tener que gestionar el doble condicionante del SEO y del Periodismo. Se argumenta sobre las fases de una campaña SEO, presentando las cuatro fases de la misma. Igualmente, se presentan y discuten los factores de posicionamiento más importantes, tanto On Site como Off Site. En relación a los primeros, se presenta también un marco o framework de optimización de noticias.

\section{Palabras clave}

SEO, Search Engine Optimization, Search Experience Optimization, Medios de comunicación, Cibermedios, Factores de posicionamiento, Factores On Page, Factores Off Page, Framework de optimización de noticias.

Otras obras de la Serie Editorial DigiDoc sobre SEO y Comunicación se pueden encontrar en:

- Página del Grupo: https://www.upf.edu/web/digidoc/editorial-digidoc

- E-Repositorio de la UPF: https://repositori.upf.edu/handle/10230/11623 


\section{Posicionamiento Web y Medios de Comunicación Ciclo de Vida de una Campaña y Factores SEO \\ Por

\author{
Lluís Codina, Carlos Gonzalo-Penela, Rafael Pedraza-Jiménez, Cristòfol Rovira \\ Grupo DigiDoc \\ Departamento de Comunicación \\ Universitat Pompeu Fabra
}

Febrero 2017

\section{Introducción: SEO y Medios de Comunicación}

SEO corresponde a las siglas Search Engine Optimization, en su acepción más extendida, o bien a Search Experience Optimization en una acepción algo más actual y que es la que nos interesa en este trabajo.

La vinculación del SEO (entendida en cualquier de las dos formas) con los medios consiste en el hecho de que éstos, no solamente necesitan hacer el mejor periodismo posible (esta parte, de hecho, es indispensable) sino que también necesitan optimizar su visibilidad en los buscadores y en las redes sociales, precisamente, como parte de su misión, e incluso, de su compromiso de calidad con los ciudadanos.

Dicho de otro, modo, el mejor periodismo también necesita un buen SEO, de lo contrario, la necesaria conexión de los contenidos periodísticos con su público queda en peligro. La simple razón es la extraordinaria abundancia de contenidos, por un lado, y los hábitos de consumo de información de los ciudadanos por otro.

La cuestión es que una parte cada vez mayor del tráfico de los medios de comunicación, o cibermedios, llega a través de la página de resultados de los buscadores (donde "buscadores" es en realidad un eufemismo por Google) y de las redes sociales, en lugar de llegar directamente 
como resultado de la navegación en su propia página web.

Es por esto que, sin acciones planificadas de posicionamiento, incluso los mejores contenidos periodísticos, como ya hemos indicamos, corren el riesgo de perder una fracción de su público natural.

\subsection{SEO general vs SEO para Cibermedios}

La pregunta que nos podemos hacer, en este contexto, es: ¿existe un SEO diferenciado para informaciones periodísticas o para medios de comunicación? La respuesta corta es que sí. La larga exige algunas apreciaciones que presentamos a continuación.

En este caso, lo primero que cabe señalar es que existe un marco general que es común para (casi) cualquier clase de SEO, y esto incluye a los medios de comunicación. Este marco común está formado, por una parte, por (1) los algoritmos de Google y de las redes sociales, y (2) por el así llamado SEO técnico.

Los algoritmos de Google son los que establecen uno de los marcos principales, dado que el objetivo de las acciones SEO es que la mayor cantidad posible de páginas de un sitio queden posicionadas entre los primeros resultados de Google para el mayor número posible de palabras clave. A grandes rasgos, estos algoritmos se aplican a los contenidos de cada página web (SEO On Page) y a los hiperenlaces de entrada de la página considerada (SEO Off Page).

Por su parte, el SEO técnico está relacionado con la configuración de los servidores de páginas web, el uso de metadatos adecuados, el uso de lenguajes como HTML y CSS, la adaptación a la web móvil, el uso de protocolos de seguridad y la velocidad de carga entre otras.

Los dos conjuntos de elementos señalados (los algoritmos de Google y el SEO técnico) afectan por igual, o sensiblemente por igual, a todos los sitios web, sean de género o contenido que sean.

Sin embargo, en algunas cuestiones importantes, hay diferencias también importantes. Por ejemplo, en el SEO técnico, los medios de comunicación deben utilizar de forma imperiosa formatos especiales para las redes sociales (Instant Articles, p.e.) y para los buscadores (AMP). También les afectan diferencias en los llamados sitemaps y en los metadatos.

Pero lo cierto es que también hay diferencias importantes en el SEO de contenidos, como intentaremos argumentar más adelante. De este modo, las diferencias consisten en muy diversos 
factores o dimensiones que afectan de forma especial a los medios de comunicación (y no a otras clases de sitios web).

No de todos ellos nos podemos ocupar aquí, pero los mencionamos para proporcionar una idea de las diferencias de contexto y naturaleza que afectan a los cibermedios en su relación con el SEO y la visibilidad en Internet. De acuerdo con nuestros análisis, los más característicos son los siguientes:

- Sitios intensivos en contenidos (SIC). En primer lugar, los medios de comunicación forman parte de los así llamados sitios intensivos en contenidos (SIC). Lo que esto significa, entre otras cosas, es que buena parte deI SEO de contenidos y de la investigación de palabras clave tiene un significado distinto del de, por ejemplo, el SEO de una tienda online o de una tienda física, así como del SEO de la mayor parte de las empresas de bienes y servicios. Por supuesto, se diferencia también, y aún más, del SEO orientado únicamente a la monetización de sitios web. En los SIC, la producción de contenidos no surge como una parte del SEO, sino que surge como una parte fundamental de la misión del sitio. Dicho de otro modo, aún sin aplicar ninguna clase de medida SEO, los SIC deben producir contenidos como parte de su misión. En este contexto, el SEO debe ajustarse a las necesidades de producción de tales contenidos, y no al revés. Afecta también a cuestiones como la llamada canibalización de palabra clave, pero también en aspectos de internal linking, etc.

- Rol central de las taxonomías. Como consecuencia de lo anterior, las taxonomías juegan un rol especialmente importante en los SIC en general, y en los medios de comunicación o cibermedios en especial. Un sistema taxonómico especialmente bien mantenido y gestionado proporciona una navegación clara, pero también un potente impacto en el SEO. Aquello que, en sitios de comercio electrónico es un claro problema: la existencia de diversas páginas sobre el mismo contenido (canibalización de palabras clave) en los medios de comunicación es una virtud gracias a las taxonomías.

- Doble condicionante. En los medios de comunicación hay un doble marco condicionante para los contenidos:

- Los principios periodísticos, que incluyen el respeto al libro de estilo de cada medio y los principios generales de ética periodística.

- Los principios SEO 
- Prevalencia de los principios periodísticos. Lo que esto significa es que, en condiciones ideales, ambos principios, periodísticos y SEO pueden confluir y alinearse para favorecer la visibilidad del sitio, pero si entran en contradicción, los que deben prevalecer son los periodísticos.

- Formatos especiales. Los medios de comunicación deben utilizar formatos especiales para que sus noticias reciban un trato adecuado en las redes sociales, en particular en Facebook y en la página de resultados de Google. Para el caso de Facebook, deben utilizar el Ilamado Instant Articles y en el de Google, el AMP. Los CMS o gestores de contenidos utilizados por los medios de comunicación, en tal caso, deben estar en condiciones de servir las noticias en esos formatos, sin necesidad de que los redactores hagan noticias distintas para cada plataforma.

- Adaptación a la web móvil. La adaptación a las pantallas de la web móvil es cada vez más importante para cualquier clase de sitio web, pero en el caso de los medios de comunicación es un imperativo categórico.

- White Hat y Black Hat SEO. Si nunca es recomendable aplicar medidas de las llamadas black hat SEO en ninguna circunstancia, en el caso de los cibermedios sería suicida (además de antiético) para el medio. Los medios de comunicación necesitan una buena reputación para tener audiencia, y las formas rápidas de conseguir enlaces o visibilidad no le sirven para nada, al revés, puede significar su ruina porque los medios de comunicación tardan en labrar su reputación y en construirse como marca de confianza, de modo que no pueden arriesgarse a tirar por la borda un trabajo de meses y años para empezar desde cero con otro dominio. 


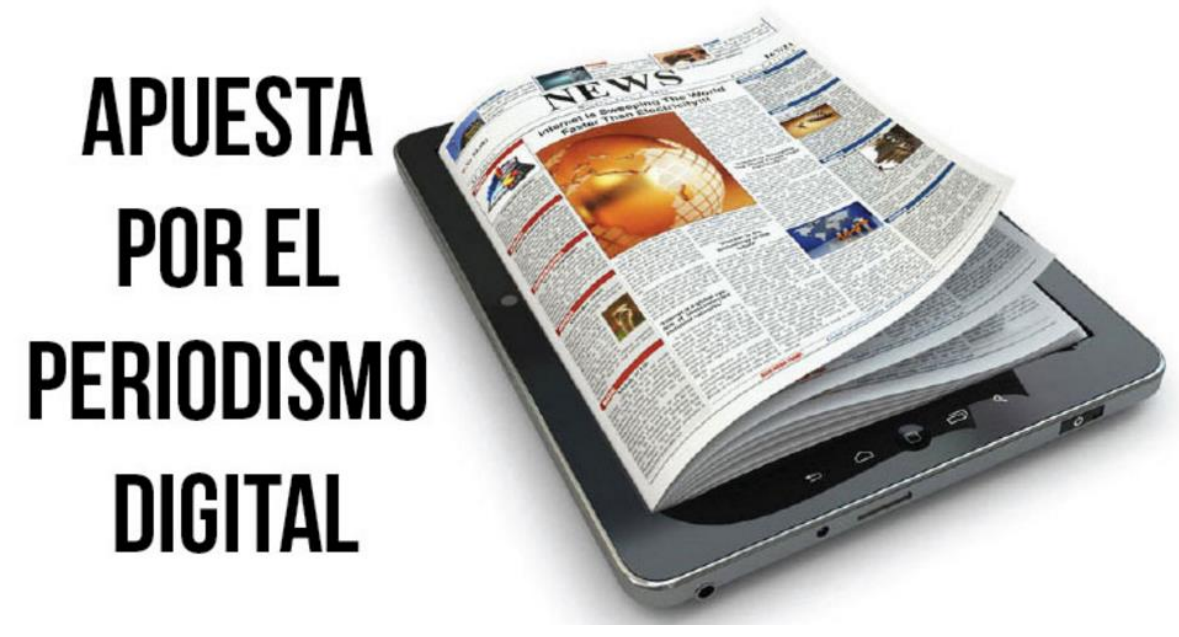

Imagen 1: Clases de Periodismo informaba que más de 400 medios digitales se han creado en España desde 2008. Nos interesan todo los medios, pero en aspectos de SEO pensamos sobre todo a estos cientos de nuevos emprendedores en el campo de la comunicación (Fuente: clasesdeperiosmo.com)

\subsection{Terminología y alcance de este trabajo}

Como ya hemos señalado, el SEO o Posicionamiento en Buscadores es un proceso cada vez más dinámico porque su contexto cada vez lo es más con la aparición (y desaparición) de actores y con los cambios en los algoritmos de buscadores y redes sociales. La cuestión, es que concebido como proceso, el SEO tiene unas fases determinadas que denominamos "ciclo de vida" por convención, ya que no existe en realidad un final en el posicionamiento de una web. Otra forma convencional de referirse a este ciclo de vida es denominarlo "campaña", cuando queremos poner el énfasis en el (re) inicio del ciclo de posicionamiento.

En este trabajo presentamos la visión global del ciclo para el supuesto del sitio de una publicación digital o cibermedio (Codina et al., 2014) que se plantea por primera vez los aspectos del SEO, bien porque es un sitio nuevo, o un rediseño o simplemente porque hasta ese momento al equipo del medio no les había preocupado el tema o no tenían aún suficientes contenidos para lanzarse a optimizar su sitio, etc. (Pedraza-Jimenez, 2013). Con tales antecedentes, para interpretar este trabajo proponemos considerar los siguientes términos:

\begin{tabular}{|l|l|}
\hline Término & Aclaración \\
\hline Cibermedio & Un sitio web dedicado a publicar noticias de actualidad con utilización \\
& $\begin{array}{l}\text { de criterios periodísticos y que dispone de un equipo de redactores } \\
\text { profesionales. Sinónimos: Publicación periódica digital, prensa } \\
\text { electrónica, medios de comunicación online, etc. }\end{array}$ \\
\hline
\end{tabular}




\begin{tabular}{|l|l|}
\hline Posicionamiento & $\begin{array}{l}\text { Posicionarse es ocupar un lugar óptimo. En el caso de Internet, consiste } \\
\text { en la capacidad de un medio para aparecer en las primeras posiciones } \\
\text { de un buscador para determinadas palabras clave, así como su } \\
\text { visibilidad en redes sociales. }\end{array}$ \\
\hline $\begin{array}{l}\text { SEO=Search } \\
\text { Optimization }\end{array}$ & $\begin{array}{l}\text { El SEO como Search Engine Optimization es el que se centra en la } \\
\text { visibilidad en las páginas de resultados de los buscadores. Es, por cierto } \\
\text { el que dio origen al término, y por eso sigue usándose incluso cuando } \\
\text { el SEO se refiere a otras clases de visibilidad, comola que proporcionan } \\
\text { las redes sociales. }\end{array}$ \\
\hline $\begin{array}{l}\text { SEO=Search } \\
\text { Optimization }\end{array}$ & $\begin{array}{l}\text { El SEO entendido como optimización de la experiencia de búsqueda } \\
\text { incluye la visibilidad en redes sociales, así como aspectos de } \\
\text { optimización basados en la arquitectura de la información y el uso de } \\
\text { taxonomías, sin dejar de lado el aspecto de los buscadores, pero en } \\
\text { este caso como un componente más, y no como el centro exclusivo del } \\
\text { SEO. En este trabajo, si no se indica lo contrario, SEO siempre lo } \\
\text { usamos en este sentido. }\end{array}$ \\
\hline
\end{tabular}

Por último, en este apartado corresponde señalar a qué clase de cibermedios o de publicaciones digitales nos dirigimos específicamente. Lo primero a señalar es que, para este trabajo en concreto, no estamos pensando en macro medios como The New York Times o El País, o similares (Rodríguez-Martínez et al., 2010).

Esta clase de medios se rigen, por así decirlo por un ecosistema propio en el que, hasta cierto punto, incluso pueden marcar sus propias "leyes" y es difícilmente exportable a otros medios. Por decirlo de alguna manera, son empresas que "quedan fuera de rango".

Por el contrario, este trabajo se dirige al 99 por ciento restante, formado por medios de comunicación de empresas medianas o pequeñas, medios que forman parte de la nueva oleada de nacidos digitales, medios centrados en temas específicos e incluso ultra específicos, o en medios generalistas, pero de ámbito local o comarcal, autonómico, etc. En otras palabras, este trabajo como otros que llevamos a cabo en nuestro grupo de investigación sobre SEO, se centra en el ecosistema creada por esos centenares de nuevos medios, nacidos digitales, tan característica de la comunicación del siglo XXI. 


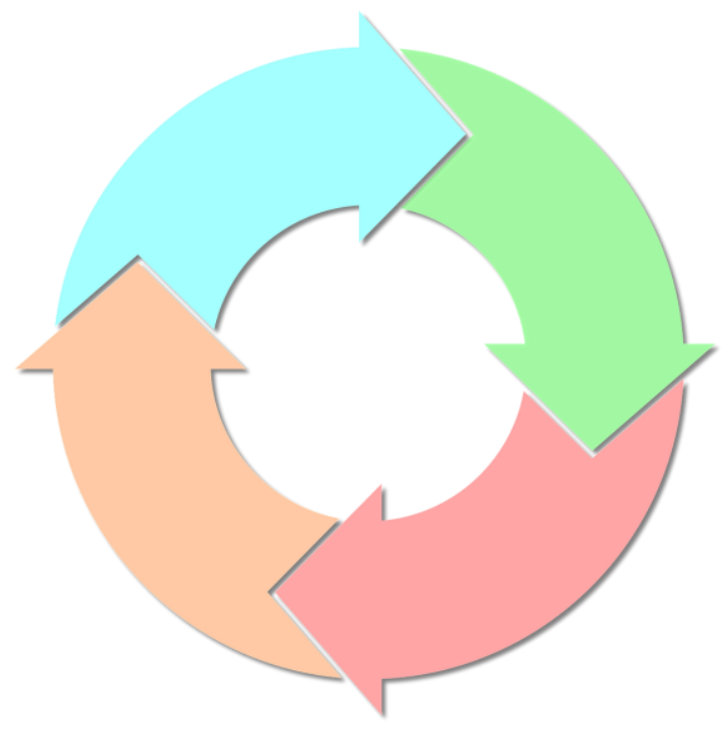

Figura 2: Aunque hablamos de fases en una campaña SEO, en realidad tienen un carácter cíclico y aún más en el caso de los medios de comunicación con variaciones constantes de su contexto (Fuente: Pixabay)

\section{Las cuatro fases de una campaña tipo $3+1$}

Podemos decir que las fases de la campaña son cuatro en total, siguiendo la fórmula " $3+1$ " porque incluye tres fases de desarrollo más una fase de seguimiento y monitorización que nos devuelve al punto 1 y siguientes de forma periódica. En todo caso, las fases son las siguientes:

1. Análisis del sitio y análisis comparativo con la competencia (Codina et al., 2016; Rovira et al., 2010).

2. Diseño de las estrategias

3. Implementación de las medidas adoptadas 
Pasado un tiempo (p.e., unas semanas) de la aplicación de las fases anteriores deberá procederse una cuarta fase $(l a+1)$ :

\section{Seguimiento de los resultados y análisis comparativo con la competencia}

Esta cuarta fase solamente marca el inicio de un proceso cíclico en el que todas las fases se seguirán, a partir de ese momento, una a otras de manera continuada en un proceso circular de que es continuo, ya que el SEO es en sí mismo un proceso de análisis y mejora constante, incluyendo episodios inevitables de ensayo y error.

La razón por la cual el SEO tiene este carácter es porque los sitios web son parte de un ecosistema en constante cambio. El propio sitio cambia: nuevas secciones, cambios de diseño, nuevos contenidos, etc. Pero el contexto cambia: se añaden otras empresas, por ejemplo, pero incluso las reglas del juego cambian, porque cambian los algoritmos de los buscadores y de las redes sociales.

\subsection{Sitio vs página}

Si volvemos a la idea de las fases, la primera pregunta que nos podemos hacer es la siguiente: ¿estas fases, se aplican a la página principal, al conjunto de la web o cada página o cada ítem noticioso (artículo, post, entrevista, etc.) publicado por separado?

La respuesta es que el SEO en general debe aplicarse a todas y cada una de las página, y por tanto, a todas las noticias que publique la web y por supuesto a la página principal. Solamente algunas secciones o páginas pueden quedar exentas.

El ejemplo típico podría ser la página de información corporativa, o las secciones de la web con avisos técnicos o legales, etc.

Lo importante es que no nos podemos limitar a optimizar la página principal, ni mucho menos. La razón es la siguiente: dada la naturaleza de la Web, no existe ninguna razón por la cual debamos suponer que los visitantes del medio en cuestión van a acceder todos a través de la página principal del mismo.

De hecho, en el caso de los sitios de medios de comunicación, es sabido que cada vez tienen más visitas a páginas de noticias concretas porque los usuarios proceden cada vez más de redes como Facebook o de las páginas de resultados de los buscadores.

En segundo lugar, si un sitio web es intensivo en contenidos, se supone que estaremos interesados en promover las páginas de las distintas secciones de modo independiente y no solamente la página principal. 
Además, nos va a interesar promocionar también las páginas de reúnen las noticias de un mismo tema, cosa que podremos hacer si utilizamos un CMS que permite trabajar el concepto de taxonomías (Codina y Pedraza-Jiménez, 2011) en base al uso de categorías o secciones y etiquetas o palabras clave. De modo que, tanto las categorías como las etiquetas van a poder convertirse en páginas que agrupen noticias por diversos criterios y aumenten el SEO del sitio para las palabras clave de tales categorías y etiquetas.

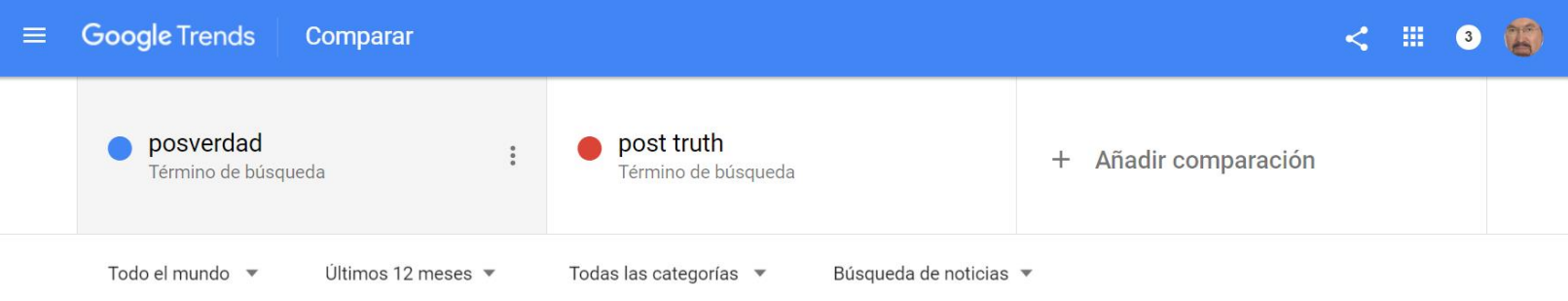

Interés a lo largo del tiempo ?

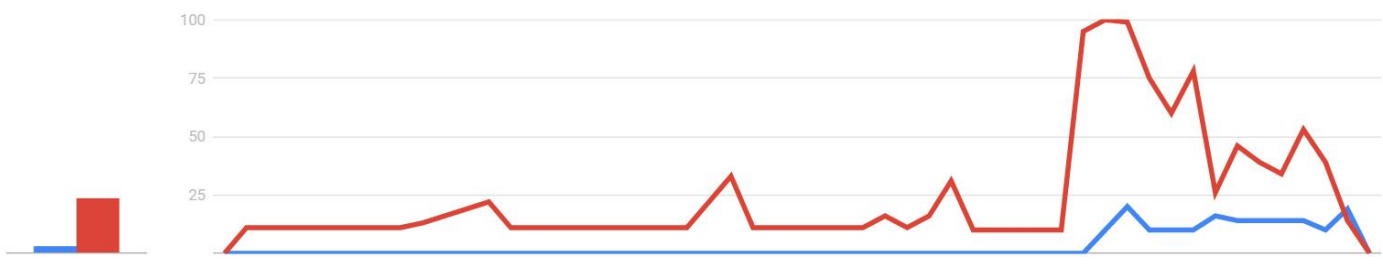

Imagen 3: Google Trends es un instrumento especialmente útil para conocer el uso de términos de búsqueda (palabras clave) por parte del público que busca noticias.

\section{Fase de análisis}

\subsection{Palabras clave}

En el SEO "estándar" el objetivo más importante de esta fase es determinar las palabras clave (keywords) para las cuales se desea optimizar el sitio (Vàllez et al., 2010). En el SEO para medios de comunicación una buena parte de este objetivo, tal vez la más importante, viene dada por la cobertura temática y el público del medio.

Es decir, un medio centrado en la actualidad política y económica, por ejemplo, no puede ignorar los temas que ocupan la agenda temática de la opinión pública, y tales temas imponen, en buena parte, las palabras clave. 
Un medio centrado en cubrir aspectos de nuevas tecnologías, o de viajes, o de moda y gastronomía, etc., se verán en una situación parecida. No obstante, incluso en la cobertura de temas de actualidad puede haber dudas de qué subtemas o derivaciones temáticas de un sector son los que puede preferir su audiencia, así como también puede haber dudas sobre qué variación de las palabras clave serán las más utilizadas por los usuarios o lectores potenciales del medio.

Además, el estudio de las palabras clave aconsejará igualmente al medio en cuestión con qué términos o expresiones los contenidos van a llegar mejor a los usuarios al captar mejor su atención.

El doble condicionante SEO vs Periodismo, indica que el estudio de las palabras clave orientará la búsqueda de temas específicos y el uso de las mejores expresiones para su audiencia, pero el libro de estilo de medio indicará la forma correcta de referirse a cada tema en caso de dudas de la existencia de términos que no se ajusten al uso correcto del idioma.

Recordemos que denominamos palabras clave a los términos de consulta que utilizan los usuarios de los motores de búsqueda. Por el mismo motivo, se denomina palabra clave a los términos presentes en el contenido de un sitio que, eventualmente, pueden coincidir con las palabras usadas por los usuarios cuando realizan sus búsquedas. Por supuesto, las palabras clave son también los términos que figuran en los índices de los motores de búsqueda (Vàllez, 2011).

Una palabra clave puede ser una palabra simple (p.e. "cine") o una expresión compuesta (p.e. "festivales de cine"). Puede ser un nombre común ("museo") o un nombre propio ("Louvre"). Puede expresar conceptos ("belleza") o cosas tangibles ("casas").

\begin{tabular}{|c|c|}
\hline TÉRMINO PREFERIDO & Sistema económico Búsqueda en UNESDOC \\
\hline CONCEPTOS ESPECÍFICOS & $\begin{array}{l}\text { Dualismo económico } \\
\text { Economía colectiva } \\
\text { Economía de mercado } \\
\text { Economía mixta } \\
\text { Economía planificada } \\
\text { Economías en transición } \\
\text { Sector privado } \\
\text { Sector público }\end{array}$ \\
\hline CONCEPTOS RELACIONADOS & $\begin{array}{l}\text { División del trabajo } \\
\text { Feudalismo }\end{array}$ \\
\hline ETIQUETA ALTERNATIVA & $\begin{array}{l}\text { Economía } \\
\text { Régimen económico }\end{array}$ \\
\hline PERTENECE AL GRUPO & Política, derecho y economía > Economía \\
\hline
\end{tabular}


Figura 4a: El Tesauro de la Unesco puede utilizarse como punto de partida en la creación de taxonomías para medios de comunicación, por la amplitud de los temas que abarca.

También pueden corresponder a ramas del conocimiento ("arquitectura") y actividades humanas ("deportes de aventura"). En los medios de comunicación, casi cualquier tipo de entidad y sus nombres genéricos y sus nombres propios pueden ser también palabras clave.

En los sitios intensivos en contenidos, como un medio de comunicación, la regla más importante consiste en que las palabras clave serán elegidas en función de los tres elementos principales que los definen: los contenidos o temas del sitio, los objetivos y el público; haciendo énfasis en este último elemento, es decir el público al que está destinada la web objeto de la campaña.

Los dos primeros componentes, contenidos + objetivos, vendrán determinados, precisamente, por la clase de periodismo que desee hacer el sitio en cuestión. Por ejemplo: ¿se trata de una nueva publicación sobre turismo cuyo objetivo principal será informar sobre la oferta cultural y gastronómica de destinos turísticos? O bien, ¿es una publicación que se centrará en el cruce entre nuevas tecnologías, gadgets, etc. y vida cotidiana? $\mathrm{O}$, incluso, ¿se trata de una publicación de tipo más generalista interesada en informar sobre política, economía y cultura en una determinada comunidad o una ciudad?

El tercero, el público, vendrá condicionado por alguno de los dos anteriores, por ejemplo, en la supuesta publicación sobre oferta cultural de destinos turísticos podemos pensar en un público joven, de tipo universitario, con un nivel de ingresos reducido, o por el contrario, en personas adultas de clase media, o media-alta, etc. 
Una vez centrados los aspectos anteriores, para ayudar a la determinación de las palabras clave existen diversos procedimientos, todos ellos con sus pros y sus contras:

- El análisis del propio sitio por un experto humano y/o con programas específicos como Moz, SEMrush, Sistrix, etc. En este caso, obtendremos un listado de palabras clave existentes en el sitio, pero perderemos la visión externa. Necesitaremos saber cuáles son las palabras clave que no estamos trabajando actualmente. Además, esta opción funciona si: (1) ya tenemos el sitio web en funcionamiento, pero no si es un sitio nuevo; (2) tenemos presupuesto para contratar esta clase de herramientas. Por tanto, las siguientes opciones son las que podemos usar si esas dos condiciones no siempre se dan.

- El análisis de frecuencias de las diversas palabras clave en la web relacionadas con el sitio y de sus diversos sinónimos utilizando los propios motores de búsqueda, algunos de los cuales suelen ofrecer otras búsquedas relacionadas. Por ejemplo, tanto en Google como en Bing, al buscar terremoto, indica como búsquedas relacionadas "maremoto", "tsunami" y "huracán", entre otras; Yahoo!, ante esa misma búsqueda, propone consultas más concretas como "terremoto en haití".

- El benchmarking por comparación de las palabras clave utilizadas en las páginas web de la mejor competencia. En este caso, es muy importante delimitar perfectamente cuál es nuestra competencia SEO y disponer de herramientas de análisis como SEMrush (es.semrush.com/) o Sistrix (www.sistrix.es). Este tipo de herramientas nos permiten ver por qué palabras clave están posicionados nuestros competidores.

- El análisis de las consultas de los usuarios, si nuestro sitio dispone de un motor de búsqueda interno. Esta suele ser una herramienta muy potente y poco explotada en la mayoría de sitios web. El análisis de los logs de nuestro buscador no sólo nos dirá qué palabras clave usan nuestros usuarios sino qué contenido esperan encontrar, algo que nos irá muy bien a la hora de priorizar la creación de contenidos.

- El análisis de las palabras más buscadas y de sus variantes respectivas que podemos obtener a través de las herramientas de algunos motores de búsqueda, en particular, la herramienta de Google tendencias de búsqueda (Google Trends) https://www.google.es/trends/. Aunque tiene bastantes limitaciones. No proporciona números absolutos y tampoco proporciona información para palabras "poco" buscadas (sin saber lo que significa poco buscadas para Google). 
- Por supuesto, hemos de utilizar las herramientas de analítica web como Google Analytics para ver qué palabras clave nos traen tráfico. Conocer esas palabras suele ser un buen punto de partida para entender cuáles son nuestros contenidos más atractivos y cómo nos buscan los usuarios.

- Pero sin duda,el instrumento más eficaz para investigar en palabras clave es Google AdWords (http://www.google.com/adwords/), o su equivalente de la competencia Bing Ads (http://advertise.bingads.microsoft.com/es-es/inicio). Son herramientas que presuponen una campaña de anuncios, pero se pueden utilizar aunque no vayamos a invertir de manera inmediata en publicidad.

- Otras herramientas específicas para obtener ideas, como Keyword Tool (http://keywordtool.io/) o Answer The Public (http://answerthepublic.com/) siempre nos ayudarán.

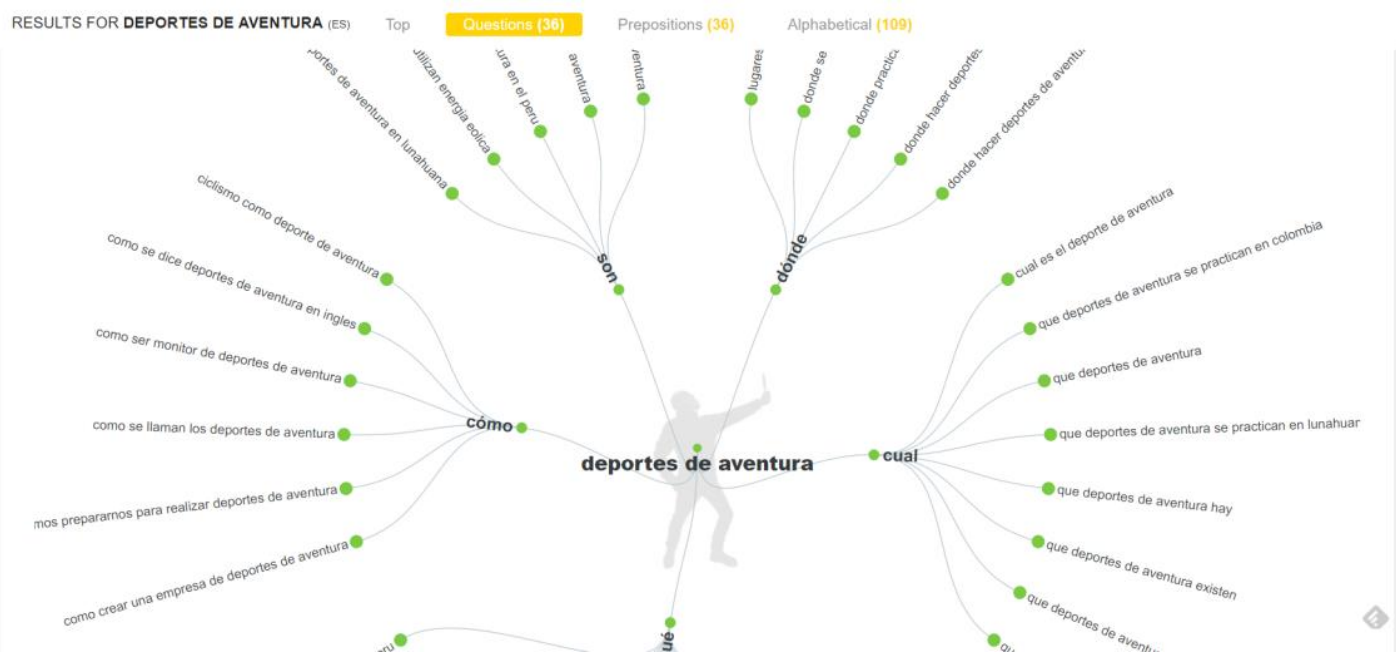

Figura 4b: Answer The Public es un sitio web que muestra las diversas formas en las que el público busca a partir de una palabra o de una frase clave.

El resultado de los análisis anteriores debería ser no solamente un buen conjunto de palabras clave, sino además varios candidatos a dos frases descriptivas del sitio.

Una de las frases, optativa, y más breve, suele denominarse tagline. Suele figurar en un lugar destacado de la página principal del sitio y se suele colocar en un lugar cercano al título principal. La tagline se puede repetir en todas las páginas del sitio. 
Esta frase forma parte del contenido visible del sitio. No todos los sitios consideran necesario disponer de una tagline (o al menos, de facto, no disponen de ella), pero lo cierto es que los sitios que la usan orientan de forma muy rápida de su contenido a los visitantes que acceden por primera vez.

La segunda frase formará parte del contenido invisible, o sea de los metadatos, ya que se usará como contenido del atributo description en la etiqueta <meta description> del código fuente, dentro de la sección <head> del código fuente y se considera imprescindible porque es la parte de los metadatos que toma Google para construir el snippet de su página de resultados (SERP).

La frase del metadato description en cada página o noticia del sitio puede tener una parte común, pero no puede ser idéntica, puesto que cada página, y aún más cada noticia, se supone que tiene un contenido que es distinto, aunque comparta elementos de tema, marca, etc.

Puede adoptarse la solución de generar dos frases para la etiqueta description: una parte muy muy corta que se puede repetir en todas las páginas de la web (p.e. el nombre de la cabecera o una palabra de tema o sección), y otra que será específica de cada página o noticia particular. La parte común (nombre del medio o nombre de la sección, irá al final, dejando la parte más prominente para la parte diferencial. La mayor parte de la descripción de cada página o noticia debe ser totalmente específica.

Podemos añadir también el metadato keywords, aunque en el caso de Google, se ha dicho reiteradamente que no tiene impacto alguno en el SEO. No obstante, se suele usar por diversas razones, en primer lugar puede facilitar las búsquedas internas, en segundo lugar parece que otros buscadores las utilizan (aunque en el caso de algunos países, como en España, la frase "otros buscadores" es un brindis al sol).

Por último, nos proporciona también una guía sobre la clase de contenidos que debemos promover para nuestro sitio, es decir, nos ayudará en la definición de la política de provisión de contenidos para nuestro sitio.

Eventualmente, si el sitio empieza ahora su primera fase de posicionamiento, pero no es un sitio de nueva creación, sino que tiene meses (o años) de antigüedad, deberíamos llevar a cabo una serie de análisis de su situación potencial.

Para ello disponemos de diversas posibilidades, pero las más habituales para un primer diagnóstico serían conocer los datos básicos en cuanto a enlaces de entrada y los datos que nos proporciona Google Webmaster Tools (ahora Search Console) y Google Analytics si ya está dado de alta el sitio y el administrador dispone de cuenta. 


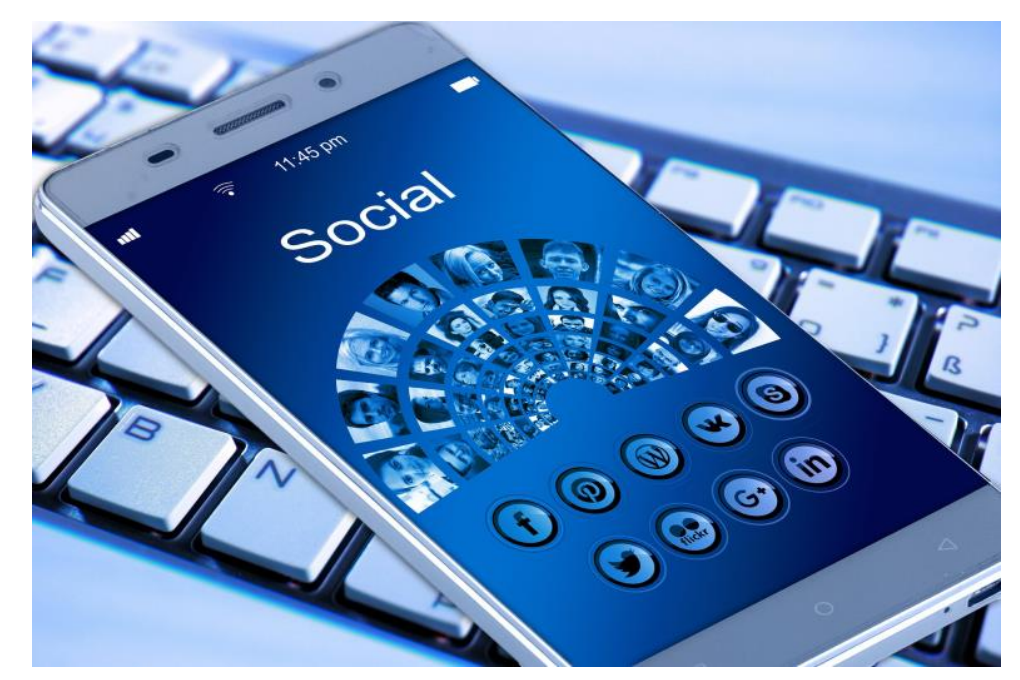

Figura 5: Las redes sociales son una de las plataformas privilegiadas de distribución de noticias.

\section{Fase de diseño}

El objetivo es presentar propuestas de optimización específicas sobre los siguientes aspectos:

\section{Contenidos del sitio:}

- Preparación de las actividades de creación de comunidad (community management) alrededor de las publicaciones del sitio. Obviamente, el medio va a necesitar cuentas en las principales redes sociales. Al menos en Facebook y en Twitter, así como un responsable de las funciones de community management.

- Asegurar que las rutinas de producción de contenidos incluyan siempre aspectos multimedia, en particular, imágenes, infografías y, por poco que sea posible, vídeo. Los sitios de medios de comunicación, en teoría, deberían publicar varias entradas al día. En todo caso, al menos, varias entradas a la semana.

- Planificación de un calendario en la creación regular de contenidos de calidad para publicar en el sitio y que estén vinculados con las palabras clave del sitio y donde éstas ocurran con naturalidad.

- Organización de las secciones del sitio de modo que la navegación contemple el uso de palabras clave en los menús del mismo.

- Uso de un sistema de subdirectorios y nombres de archivos que faciliten el uso de URL con palabras clave. 
- Utilización de un sistema de categorías (entre 2 y 10) y de etiquetas (tantas como necesitemos). Es lo que algunos CMS como WordPress consideran las taxonomías. Las categorías pueden equivaler a los principales ítems del menú de navegación así que no debemos tener muchas. Las etiquetas corresponden a las palabras clave de cada entrada publicada en la web, y podemos tener tantas como sea necesario (Vállez, 2015).

\section{Código fuente del sitio:}

- Descripciones adecuadas en el atributo description, así como contenido del elemento <title> en la sección <head> de cada página, así como el atributo author si se considera oportuno especificar el nombre o nombres de los autores personales o corporativos del sitio.

- El snippet de la SERP de Google se construye con los metadatos <title> y <meta description>.

- Aparición de las palabras clave más importantes en el atributo title en los enlaces de navegación interna y en los enlaces externos y en el atributo alt en los elementos multimedia.

- Aparición de las palabras clave principales en títulos de los enlaces y en títulos de secciones (etiquetas $\langle\mathrm{h} 1\rangle,\langle\mathrm{h} 2\rangle$, etc) y al menos una vez en palabras del cuerpo en negrita.

Si, como es habitual, se crea el sitio web con un gestor de contenidos (WordPress, p.e.), habrá que identificar los apartados de la configuración o de la creación de páginas que generan estas etiquetas.

A menudo la creación de las etiquetas $<$ meta $>$ y $<$ title $>$ se llenan automáticamente a partir de la información proporcionada en los títulos de las páginas o posts, las etiquetas $\langle\mathrm{h} 1\rangle$, $\langle\mathrm{h} 2\rangle$, etc son también generadas automáticamente al marcar los títulos con el editor wysiwyg. Igualmente, el atributo alt de las imágenes se llena al subir una imagen con el editor. En cada gestor de contenidos se tendrá que hacer un control de de su funcionamiento para asegurar estos aspectos básicos para el posicionamiento.

En el caso de gestores como WordPress, tenemos la posibilidad de añadir plugins muy potentes, como Yoast SEO o All in One SEO que permiten un control total sobre los dos componentes mencionados del snippet, <title $>\mathrm{y}<$ description $>$. 


\section{Enlaces:}

- Lista de sitios web que podrían enlazar nuestro sitio con el correo electrónico del administrador del sitio o cualquier otra dirección de contacto para proponer que nos enlace.

- Lista de directorios o sitios de la web social donde podemos abrir cuentas y distribuir contenidos que enlacen a nuestro sitio

\section{Fase de implantación}

\subsection{Subfase I: Aprovisionamiento de enlaces de entrada}

Sea cual sea nuestro propósito y estrategia SEO, y a pesar de la muy debatida caída de importancia del PageRank es importante proveerse de enlaces de entrada. De este modo, cuando los motores entren en nuestro sitio y lo analicen, descubrirán que ya tenemos ese ingrediente tan importante para obtener buenos rankings en las páginas de resultados.

Además, mejoraremos la frecuencia con la que estos robots nos visitan. Es muy importante que estos enlaces tengan sentido y sean temáticamente relevantes, dado que los buscadores pueden llegar a penalizar aquellos sitios que abusan de la creación de enlaces artificiales.

Podemos aplicar estas acciones:

- Altas en directorios y portales temáticos o regionales. Un buen punto de partida si no conocemos ninguno puede consistir en consultar el directorio Dmoz.

- Captación de enlaces corporativos y de sitios de temática similar. Además de los enlaces que nuestro sitio puede obtener de los directorios anteriores, sin duda podremos obtener enlaces de otros sitios; p.e. de otras webs vinculadas con nuestra institución, así como de otras webs con contenidos similares (siempre es conveniente demostrar que nosotros ya los hemos enlazado).

- Política de creación de cuentas en sitios de la web social. Si queremos tener una presencia seria en la Web Social, hemos de considerar: Pinterest, Facebook, LinkedIN, Twitter, Google Plus y Tumblr. También deberíamos pensar en un canal en YouTube si tenemos la previsión de crear contenidos en vídeo.

- Política de difusión de los contenidos a través de nuestras cuentas y canales en las redes sociales mencionadas. El medio debe disponer de una actividad de gestión de la comunidad, en la figura de una persona dedicada, aunque sea a tiempo parcial. 
- Política de creación de varios blogs (dependiendo de la dimensión y recursos humanos del sitio) con contenidos relacionados con nuestro sitio, y con la consiguiente relación de enlaces hacia nuestro sitio.

\subsection{Subfase II: Alta en Search Console}

Los principales motores de búsqueda tienen una elevada capacidad de rastreo e indexación (Google, Bing, Yahoo, Yandex, etc.), así que en teoría no sería necesario dar de alta nuestro sitio web en los buscadores, pero nos conviene asegurarnos, así como necesitaremos acreditarnos como administradores autorizados de un sitio para poder consultar los datos de analítica que nos proporcionan los buscadores como Google y Bing.

La acción más recomendable es dar de alta nuestro sitio en las herramientas de los buscadores que permiten hacer un seguimiento de su presencia en sus índices, como por ejemplo:

- Google Search Console

- Bing Toolbox Webmaster

Esta alta nos permitirá controlar aspectos como el número de páginas indexadas, las palabras clave que nos traen tráfico o recibir mensajes sobre el estado de nuestra página web.

Adicionalmente también puede ser interesante dar de alta nuestro sitio en Yandex o Baidu Webmaster Tools, aunque estos últimos sólo serán necesarios si tenemos una orientación internacional (China o Rusia principalmente).

\section{Fase de seguimiento}

\subsection{Calendario}

Entre el final de la campaña y el primer seguimiento es aconsejable esperar un tiempo. En función del tipo de contenido y de las herramientas usadas para crear el sitio web este tiempo puede ser unas horas o unas semanas. A menudo monitorizar resultados sin esperar a que los buscadores actualicen los índices puede resultar a la vez frustrante y engañoso. Por tanto, es importante asegurarnos que estamos poniendo todas las condiciones para que se produzca una reindexación frecuente:

- Alta en las herramienta de WebMaster Tools y petición explícita de la indexación

- Actualización frecuente de la propia página web

- Procurar que haya enlaces entrantes 


\subsection{Herramientas}

Lo primero que haremos será constatar que nuestro sitio ha sido indexado. Para ello, algunos motores disponen de un comando que permite conocer si nuestro sitio figura en su índice y cuantas páginas de nuestro sitio han sido indizadas.

Tanto en Google como en Bing el comando es site. Por ejemplo, si queremos saber si la web de la UPF está indizada en Google y cuántas páginas ha indizado podemos utilizar este comando así: site:www.sitioweb.com como muestra la imagen siguiente:

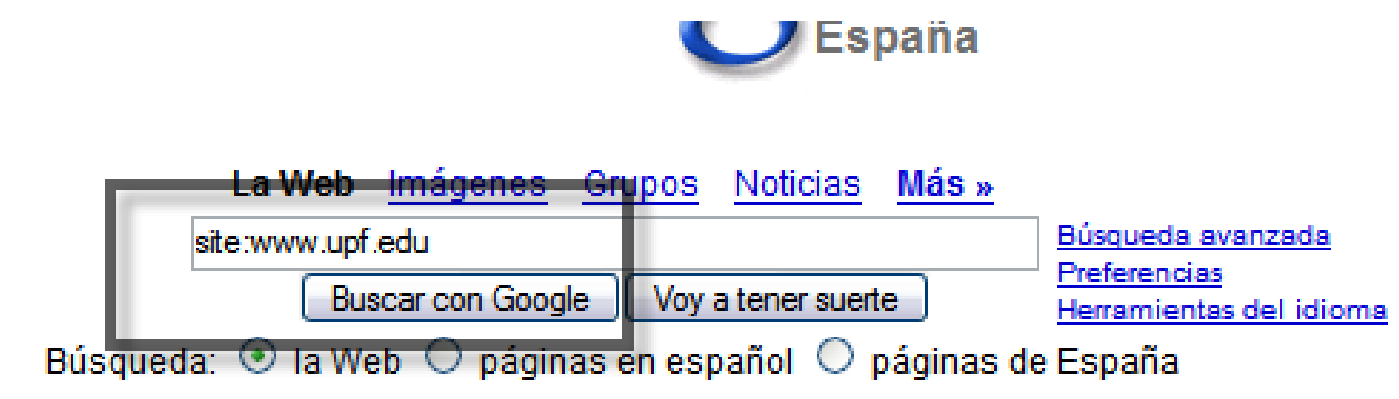

Figura 6. Uso del comando site

Las herramientas de WebMaster Tools existen diversos apartados para hacer un seguimiento de la indexación. Por ejemplo en Google WebMaster Tools da información sobre:

- Errores de rastreo

- Estadísticas de rastreo

- URL bloqueadas

- Estado de indexación 


\section{Google}

Herramientas para webmasters de Google

Panel del sitio

Mensajes del sitio

- Aspecto de la búsqueda $\mathbf{A}$

- Tráfico de búsqueda

- Inarice de Google

Estado de indexación

Palabras clave de conter do

Eliminación de URL

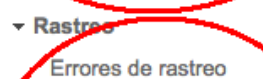

Errores de rastreo

Estadísticas de rastreo

Explorar como Google

URL bloqueadas

Sitemaps

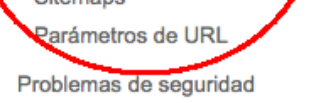

Otros recursos

- Labs

\section{Estadísticas de rastreo}

Actividad de Googlebot en los últimos 90 días

Páginas rastreadas al día

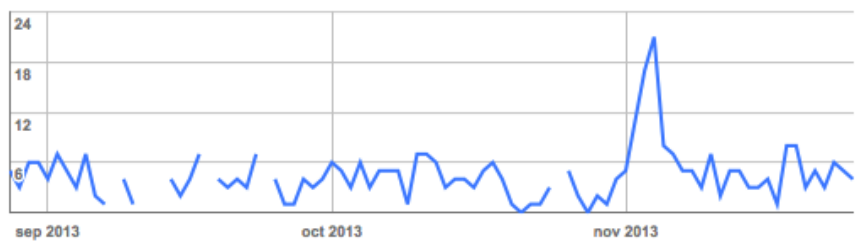

Kilobytes descargados al día

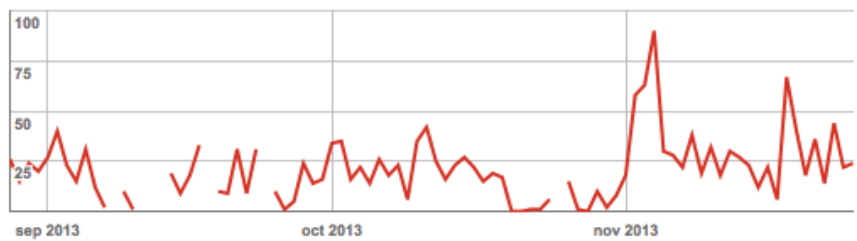

Figura 7: Parte de las herramientas de análisis de Google Console

Una vez sepamos que nuestro sitio ha sido indizado, la comprobación más importante consistirá en hacer búsquedas por las diversas palabras clave para las cuales hemos optimizado nuestro sitio y anotar en qué posición queda en la página de resultados de cada motor. El objetivo debe ser aparecer en la primera página de resultados y, a ser posible, entre los cinco primeros. Si no lo hemos conseguido, las causas pueden ser de tres tipos:

- Técnicas: tal vez el sitio presenta algún problema de indización a los motores. Por ejemplo, el sitio puede usar tecnologías obsoletas, como frames (marcos). La prueba anterior (el comando site) pondrá esto de manifiesto si, por ejemplo, solamente una parte muy pequeña de la web ha sido indizada.

- De contenido textual: Tal vez el sitio presenta escaso contenido con ocurrencia de las palabras clave que se habían seleccionado para optimizar.

- De contenido multimedia: El sitio puede carecer de contenido multimedia, un factor cada vez más importante, o el contenido multimedia está mal tratado desde el punto de vista de los metadatos. 
- De popularidad: Tal vez el sitio dispone de pocos enlaces de entrada de sitios que a su vez sean muy populares. Aquí podemos utilizar numerosas herramientas para conocer el número y calidad de los de enlaces entrantes. Algunas de las más populares son Majestic SEO (www.majesticseo.com/) y Open Site Explorer (www.opensiteexplorer.org/). Igualmente, podemos monitorizar el TraffickRank de nuestro sitio a través de la toolbar de Alexa (www.alexa.com ).

Las causas técnicas deberían poder resolverse sin mayores problemas. El uso de frames para crear páginas está de hecho, desaconsejado desde hace tiempo, y los modernos sistemas de creación de páginas web presentan muchas opciones para ello, la principal, el uso de hojas de estilo. Los sistemas de gestión de contenidos también se pueden parametrizar para que creen menús con enlaces fáciles de seguir por los motores de búsqueda, etc.

En cuanto a los problemas de contenido, no existe una solución fácil ni rápida (ni económica, debemos añadir), y aunque a muchos les pueda extrañar, es justo que sea así.

Nadie espera en realidad que los motores de búsqueda concedan las primera posiciones a webs con contenidos irrelevantes para la pregunta. Por tanto, si nuestra web posee pocos contenidos sobre las palabras clave por los que deseamos obtener buenas posiciones, la única solución es planificar un calendario de producción y publicación de tales contenidos. Ni siquiera sirve añadir toneladas de metadatos (en etiquetas <meta>) porque los motores de búsqueda han aprendido a desconfiar de ellos. Para los motores de búsqueda es una cuestión de supervivencia promocionar a buenas posiciones solamente a sitios con buenos contenidos en calidad y en cantidad.

Por lo que hace a la popularidad, si se han dado los pasos del punto 3.3 para obtener enlaces y pese a todo nuestro sitio dispone de pocos enlaces de entrada, la razón principal solamente suele ser simplemente que los otros webmasters no han considerado interesante nuestro sitio, bien por tener pocos contenidos, bien por ser de poca calidad o poco originales o por una combinación de todo esto. Por tanto, el problema de la popularidad como se puede ver va ligado con el de los contenidos y, en teoría, resolver el primero debería resolver el segundo, siempre que se den los pasos indicados en el punto 3.3. 


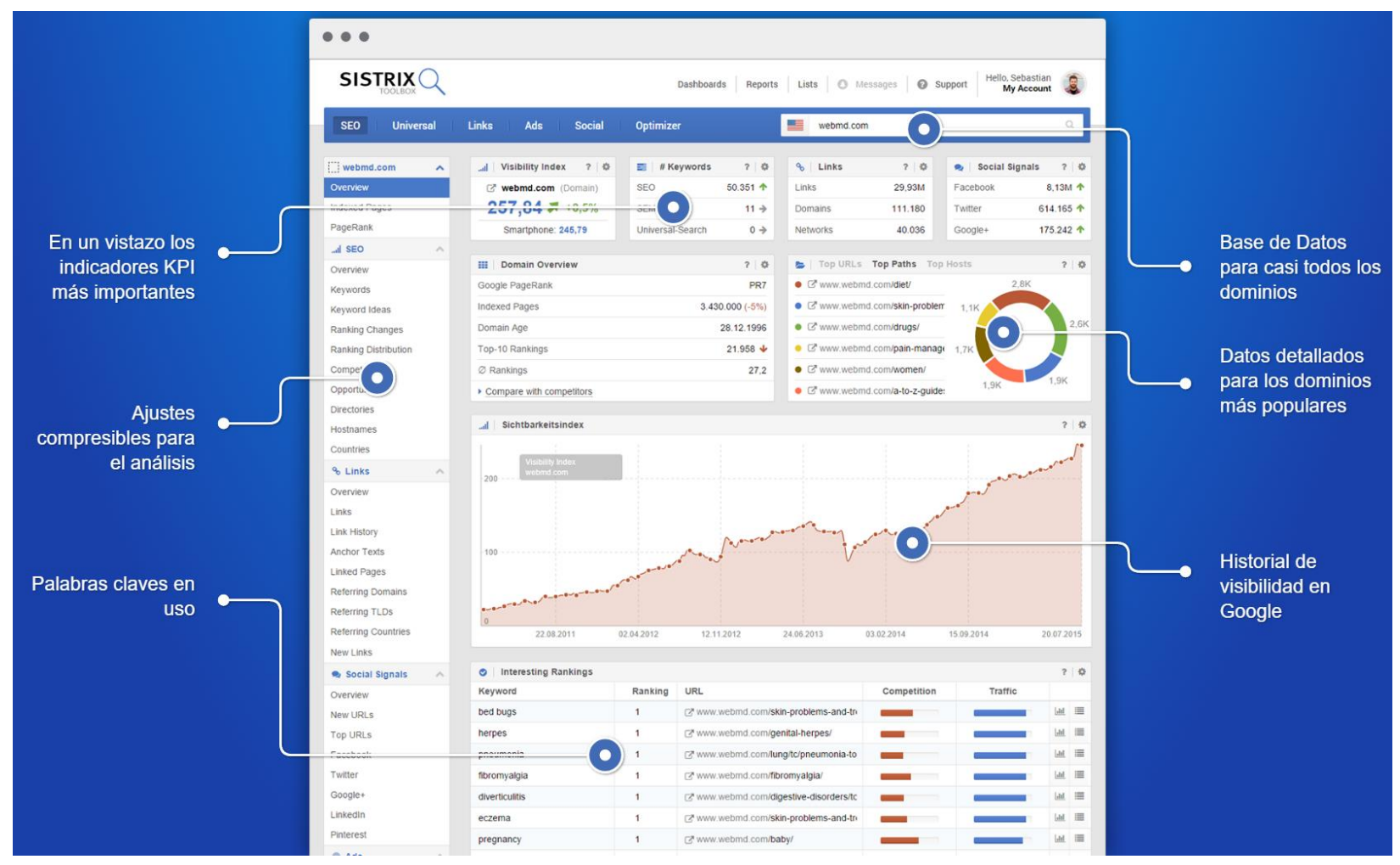

Figura 8: Sistrix es una herramienta de análisis muy utilizada por medios de comunicación de nuestros país. Otras herramientas muy utilizadas son SEMrush, Ahrefs, Moz y Majestic.

\section{Análisis de la competencia}

Ningún análisis SEO está completo si no nos comparamos con nuestra mejor competencia. Deberemos seleccionar varios sitios con los que medir nuestros resultados. Cuántos sitios exactamente es una cuestión de tiempo y presupuesto; y también de lo atomizado o de lo competitivo que sea nuestro mercado o sector informativo. En cualquier caso, parece que compararnos al menos con los tres sitios de la competencia puede ser un buen estándar.

Los ítems que podemos medir utilizando algunas de las herramientas gratuitas (o si pueden ser de pago, mejor ya que son mucho más completas) que ya hemos mencionado como SEMRush, Moz, Majestic SEO, Woorank, Ahref, o Alexa nos proporcionarán indicadores importantes con los que medirnos. Entre ellos:

- Enlaces de entrada: número, composición de los mismos y procedencia de los mismos

- Tiempo de permanencia

- Tasa de rebote

- Número de páginas vistas 
- Número de página indizadas

- Posición de las páginas de la competencia para determinadas palabras clave

- Web social: presencia e interacciones de la competencia en la web social

Algunos programas como Moz, Majestic o Ahref además tienen indicadores propios, generalmente alrededor de conceptos como la autoridad del dominio o la reputación del dominio o de la página, basados a su vez en variaciones del análisis de enlaces.

Será este análisis de la competencia el que nos dirá hasta qué punto hemos estado acertados en nuestras acciones, y sobre todo, será su reiteración cada cierto tiempo, por ejemplo, una vez al mes, el que confirmará si debemos mantener nuestras políticas actuales o debemos pensar en realizar cambios.

\subsection{Software de análisis SEO}

Los dos puntos anteriores nos están diciendo que tiene poco sentido invertir en la creación de una publicación digital y no invertir en la contratación de una herramienta de análisis SEO de pago. Las tarifas difícilmente van a arruinar a una empresa, incluso a una empresa pequeña, porque existen posibilidades que van desde la contratación mensual por unas pocas decenas de euros, hasta contrataciones anuales por unos pocos centenares. También hay tarifas mucho más altas, pero entendemos que no sería el caso de un cibermedio. Son tarifas pensadas para agencias de SEO, lo que no es el caso.

Nuestra experiencia nos dice que dos de las mejores del mercado, por su cuadro de tarifas bastante accesible y al mismo tiempo por la amplitud de sus herramientas son Sistrix, ampliamente utilizada en medios de comunicación y SEMrush, de amplio espectro de uso.

Otras herramientas que gozan de amplia reputación son Ahrefs, Moz, y Majestic. El lector interesado puede consultar un directorio mantenido por uno de los autores donde aparece una amplia selección de herramientas SEO, incluyendo algunas de uso gratuito (https://www.lluiscodina.com/recursos-seo/).

\section{Las barreras}

Una vez, hemos examinado las fases de una campaña, conviene repasar cosas que, tal vez tengamos muy claras, pero tal vez no tanto. Por si acaso, en lo que sigue consideraremos algunas barreras y después revisaremos los factores clave de posicionamiento. 
Como tal vez se desprenda de lo anterior, la barrera número uno al posicionamiento web de un sitio es el propio sitio: si no tiene contenidos de interés, ¿cómo esperamos que obtenga tráfico?, En el caso de los medios de comunicación estos contenidos, al menos en parte, deben ser propios y originales.

Además, deben mostrar que los redactores han procedido a aplicar las mejores rutinas periodísticas: consulta a fuentes directas, contrastación de datos, verificación de información, buenas prácticas de redacción, imágenes y vídeos de calidad, etc. Nadie dice que esto sea fácil de conseguir. Al contrario, constituye la parte principal del presupuesto de mantenimiento de un sitio, ahora que los aspectos tecnológicos del mantenimiento son más fáciles gracias a los gestores de contenidos.

Lo cierto es que hay "otras" barreras que se refieren a sitios que, pese a tener un contenido valioso, no quedan bien posicionados. Los motivos pueden ser muy variados, pero los tres más comunes suelen ser estos:

- Actualmente es infrecuente, pero aún nos podemos encontrar con que simplemente, nadie se ha encargado de promocionar el sitio mediante enlaces desde directorios sectoriales o sitios temáticamente afines al medio de comunicación.

- La tecnología utilizada para codificar el sitio impide que los motores de búsqueda puedan interpretarlo: por ejemplo, el sitio utiliza muchos gráficos y poco texto, o bien utiliza técnicas obsoletas como marcos (frames), o utiliza de forma incorrecta tecnologías como JavaScript, Flash, etc., que impiden que los motores de búsqueda puedan explorar de forma adecuada el sitio ya que carece de contenido textual.

- El diseño de la navegación impide que las "arañas" de los buscadores puedan recorrer la totalidad del sitio y copiar de forma adecuada los contenidos para crear sus índices. Esto puede deberse a una cantidad de motivos técnicos, en general, problemas de configuración del servidor, que deben revisarse.

\section{La lista esencial}

A continuación, presentamos la lista de los aspectos esenciales de chequeo para el posicionamiento de un sitio web. Es habitual separar los factores de posicionamiento en factores tipo On Page y Off Page, es decir, aquellos que están bajo nuestro control y los que no podemos controlar (o al menos, no del todo). En la lista siguiente los identificamos mediante un sistema de colores: On Page > color rojo, Off Page > color azul 


\begin{tabular}{|l|l|}
\hline $\begin{array}{l}\text { Aspecto o } \\
\text { factor }\end{array}$ & Descripción \\
\hline $\begin{array}{l}\text { Tema y } \\
\text { contenido del } \\
\text { sitio }\end{array}$ & $\begin{array}{l}\text { El contenido del sitio debe estar claramente enfocado en el tema o } \\
\text { temas principales del mismo, mediante contenido textual en cualquiera } \\
\text { de los formatos periodísticos que el medio considere necesario atender, } \\
\text { siempre acompañados por contenidos multimedia. Los criterios de } \\
\text { producción periodística serán aquí los determinantes. }\end{array}$ \\
$\begin{array}{l}\text { Estimaciones recientes (por ejemplo del fabricante del plugin SEO } \\
\text { Yoast) nos dicen que cada noticia debería tener al menos 300 palabras } \\
\text { para tener alguna importancia. Naturalmente, cada sector puede } \\
\text { presentar diferencias y la creciente competencia hace que cada vez se } \\
\text { necesite todavía más volumen de contenidos en sectores muy } \\
\text { competitivos. } \\
\text { calidad }+ \\
\text { volumen }\end{array}$ & $\begin{array}{l}\text { Del enunciado anterior, se deduce que no podemos esperar están bien } \\
\text { posicionado si los buscadores no tienen con qué posicionarnos. Ese qué } \\
\text { son los contenidos. Pero en la web actual no nos servirá cualquier } \\
\text { contenido. Deben cumplir varias condiciones: (1) ser originales; (2) de } \\
\text { calidad; (3) abundantes y actualizados. }\end{array}$ \\
\hline $\begin{array}{l}\text { Deben ser originales, no en el sentido de extravagantes o ratos, sino en } \\
\text { el sentido de contenidos propios, no tomados de otro sitio y también en } \\
\text { sentido de que no sean contenidos duplicados, ya presentes en otras } \\
\text { secciones o en otros sitios de nuestra web. Algunos de los últimos } \\
\text { algoritmos de Google se dedican, precisamente a descartar páginas de } \\
\text { las primera posiciones si detectan que tiene muchos contenidos } \\
\text { duplicados, es decir, repetidos o copiados de otros sitios. }\end{array}$ \\
$\begin{array}{l}\text { Deben ser de calidad. No sirven contenidos mediocres. La web está } \\
\text { repleta de contenidos de buena calidad.e incluso de muy buena calidad. } \\
\text { Bien diseñados y elaborados con informaciones y datos procedentes de } \\
\text { trabajo de campos, de entrevistas, de estudios bien elaborados o de } \\
\text { prácticas de curación de contenidos muy selectivas. } \\
\text { También deben ser abundantes y renovados con frecuencia, es decir, } \\
\text { debemos ir incorporando contenidos nuevos al menos con frecuencia }\end{array}$ \\
\hline
\end{tabular}




\begin{tabular}{|c|c|}
\hline & $\begin{array}{l}\text { semanal y a ser posible, con frecuencia diaria. } \\
\text { Además, de un medio de comunicación (no de un blog) se espera que } \\
\text { haya diversos autores, es decir, diversos redactores, por tanto, se } \\
\text { espera diversidad también en este aspecto. } \\
\text { Alguno de los algoritmos recientes de Google está especializado en } \\
\text { detectar páginas con contenidos pobres, o sobre optimizados para el } \\
\text { SEO, o con exceso de anuncios o publicidad intrusiva. En concreto, al } \\
\text { parecer, una de las directivas de estos algoritmos consiste en degradar } \\
\text { posiciones en el caso de páginas que la mitad superior de la misma está } \\
\text { llena de anuncios, es decir, que los contenidos reales no aparecen hasta } \\
\text { hacer varios clics en la barra de desplazamiento vertical del navegador. } \\
\text { En la siguiente fila se insiste, además en otra cosa: los sitios deben tener } \\
\text { contenido multimedia. }\end{array}$ \\
\hline $\begin{array}{l}\text { Multimedia: } \\
\text { esencial }\end{array}$ & $\begin{array}{l}\text { Es muy difícil quedar bien posicionados sin contenidos multimedia, y } \\
\text { por esto entendemos: } \\
\text { - Fotografías } \\
\text { - Gráficos } \\
\text { - Vídeos } \\
\text { - Infografías } \\
\text { Necesitaremos una política de creación de contenidos sobre los temas } \\
\text { de nuestro sitio que vaya incorporando materiales multimedia: vídeo } \\
\text { (tutoriales, por ejemplo o demostraciones de producto), imágenes } \\
\text { (fotografías de productos o de nuestras instalaciones) e infografías, } \\
\text { (consejos, estudios del sector, trucos y habilidades técnicas, etc.) }\end{array}$ \\
\hline $\begin{array}{l}\text { Diseño: } \\
\text { moderno y } \\
\text { atractivo }\end{array}$ & $\begin{array}{l}\text { Los sitios web de éxito siguen unas pautas de diseño muy exigente. Hay } \\
\text { tendencias claras de diseño actuales donde se imponen las grandes } \\
\text { imágenes, tipografía ultra clara, abundancia de blancos, una variedad } \\
\text { de familias tipográficas y colores variados, pero bien combinados, } \\
\text { sistemas de navegación atractivos y todo muy equilibrado. } \\
\text { Afortunadamente, si trabajamos con un CMS como WordPress } \\
\text { podemos encontrar temas con excelentes diseños por precios } \\
\text { asequibles. Es decir, actualmente, un sitio web puede tener un aspecto }\end{array}$ \\
\hline
\end{tabular}




\begin{tabular}{|l|l|}
\hline $\begin{array}{l}\text { Arquitectura } \\
\text { de la } \\
\text { Información y } \\
\text { etiquetas }\end{array}$ & $\begin{array}{l}\text { muy cuidado y de gran diseño con presupuestos al alcance de una } \\
\text { pequeña o mediana empresa. } \\
\text { navegación en el sitio debe ser intuitiva y muy consistente. En el menú } \\
\text { principal, los usuarios esperan encontrar pocas categorías, alrededor de } \\
\text { una decena, sin perjuicio de que, a su vez, cada categoría principal } \\
\text { pueda tener subcategorías, lo que nos conduce a un menú rico en } \\
\text { opciones, pero fácil de navegar. }\end{array}$ \\
$\begin{array}{ll}\text { Un buen sistema de categorías y de etiquetas constituye la base para } \\
\text { después disponer de un sistema de navegación asociado que retenga a } \\
\text { los usuarios y reduzca las tasas de rebote. }\end{array}$ \\
$\begin{array}{l}\text { Los sistemas de CMS como WordPress hacen muy fácil gestionar y } \\
\text { asignar etiquetas (palabras clave) y categorías (clases) a las páginas de } \\
\text { un sitio. El uso de estas etiquetas y categorías permite asociar páginas } \\
\text { del mismo tema a cada página, y mejorar asíla navegación mediante } \\
\text { enlaces a entradas relacionadas. Como decimos, esto retiene a los } \\
\text { visitantes y mejora el posicionamiento. }\end{array}$ \\
\hline Palabras clave \\
$\begin{array}{l}\text { Las palabras clave que expresan los temas del sitio debe estar bien } \\
\text { representadas en las páginas de contenido del sitio y estratégicamente } \\
\text { distribuidas en títulos (etiquetas h1, h2, etc.), negritas y texto de } \\
\text { enlaces, pero siempre de una forma natural, es decir, sin repetir esas } \\
\text { palabras clave de una forma carente de sentido, lo que sería } \\
\text { considerado como un caso de sobre optimización SEO y penalizado por } \\
\text { Google. }\end{array}$ \\
$\begin{array}{l}\text { Deben estar también en la taxonomía del sitio: categorías de } \\
\text { navegación y etiquetas, así como en las URL internas. Más adelante } \\
\text { mostramos un framework específicamente dirigido a la optimización } \\
\text { SEO de noticias. }\end{array}$ \\
\hline
\end{tabular}




\begin{tabular}{|c|c|}
\hline URL & $\begin{array}{l}\text { Es ideal que la URL del sitio contenga alguna de las palabras clave } \\
\text { esenciales del sitio. Por ejemplo, un sitio sobre historia del arte, debería } \\
\text { tener una URL como ésta: www.historiadelarte.com } \\
\text { La estructura de la navegación del sitio, en los nombres de las opciones } \\
\text { de los menús, y en las URL de las páginas individuales también deben } \\
\text { tener en cuenta el SEO y usar URL con palabras clave del contenido. } \\
\text { Hay que evitar las URL generadas automáticamente mediante ristras de } \\
\text { caracteres sin sentido. En su lugar, necesitamos URL no muy largas y con } \\
\text { palabras clave como parte de las URL }\end{array}$ \\
\hline $\begin{array}{l}\text { Metadatos y } \\
\text { Código Fuente }\end{array}$ & $\begin{array}{l}\text { Aunque no tiene un enorme impacto en el posicionamiento, los } \\
\text { metadatos <title> y <meta description> son esenciales porque forman } \\
\text { parte del snippet de la SERP. } \\
\text { Por tanto, su importancia es grande en cuanto al ratio de clics en la } \\
\text { SERP. Cuanto mejor sea nuestro snippet, más clics conseguiremos en la } \\
\text { SERP. Y existe bastante consenso en que Google tiende a hacer perder } \\
\text { posiciones a las páginas que obtienen un ratio de clics bajo en la SERP. } \\
\text { En cuanto al código fuente, como seguramente trabajaremos con un } \\
\text { CMS como WordPress o similar, lo que debemos hacer es asegurarnos } \\
\text { de que nuestro CMS usa HTML5 y un diseño de tipo responsive para } \\
\text { compatibilidad con la web móvil. }\end{array}$ \\
\hline $\begin{array}{l}\text { Adaptación a } \\
\text { la Web Móvil }\end{array}$ & $\begin{array}{l}\text { Hace ya tiempo que los sitios reciben una proporción de tráfico muy } \\
\text { importante de la web móvil (sobre todo smartphones). Algunas clases } \\
\text { de sitios, por ejemplo, hoteles o restaurantes, así como muchos } \\
\text { negocios locales reciben ya más tráfico de dispositivos móviles que de } \\
\text { escritorio. } \\
\text { Además, Google asegura que penaliza con posiciones más bajas a los } \\
\text { sitios que no están adaptados a la web móvil mediante un sistema } \\
\text { responsive. Esto enlaza con el apartado del código fuente. }\end{array}$ \\
\hline
\end{tabular}




\begin{tabular}{|c|c|}
\hline $\begin{array}{l}\text { Enlaces de } \\
\text { entrada }\end{array}$ & $\begin{array}{l}\text { Pese a la caída de importancia del PageRank, es muy importante } \\
\text { conseguir el máximo número de enlaces procedentes de otros sitios y } \\
\text { de interacciones con la web social. } \\
\text { Si el sitio proporciona contenidos de interés y los renueva con } \\
\text { frecuencia, irán llegando otros enlaces de forma natural, pero los } \\
\text { responsables del SEO de cada medio deben pensar siempre en formas } \\
\text { proactivas de conseguir enlaces de entrada, como la inscripción del sitio } \\
\text { en directorios temáticos. }\end{array}$ \\
\hline $\begin{array}{l}\text { Profundidad } \\
\text { de indización }\end{array}$ & $\begin{array}{l}\text { Los motores de búsqueda deben integrar el máximo número de páginas } \\
\text { de nuestro sitio en su índice. } \\
\text { Deben hacerse comprobaciones con los motores de búsqueda y las } \\
\text { herramientas de análisis del servidor para corregir posibles problemas } \\
\text { con la indexación del sitio por parte de los buscadores. }\end{array}$ \\
\hline $\begin{array}{l}\text { Mantener la } \\
\text { URL }\end{array}$ & $\begin{array}{l}\text { Juega muy malas pasadas cambiar la URL. Los sitios que mantienen la } \\
\text { misma URL a lo largo de años, se benefician de esa antigüedad en forma } \\
\text { de mejor posicionamiento. } \\
\text { Si no tenemos más remedios que cambiar la URL hay que adoptar una } \\
\text { política cuidadosa de redirecciones de la antigua URL a la nueva para } \\
\text { minimizar el impacto. }\end{array}$ \\
\hline Frames & $\begin{array}{l}\text { Se debe evitar, a toda costa, usar frames (marcos) para su sitio. Utilice } \\
\text { en su lugar hojas de estilo (CSS). Este consejo, afortunadamente está } \\
\text { casi obsoleto si utilizamos gestores de contenidos (CMS) de calidad. }\end{array}$ \\
\hline $\begin{array}{l}\text { Multimedia } \\
\text { basado en } \\
\text { Flash }\end{array}$ & $\begin{array}{l}\text { Recuerde que los motores de búsqueda no entienden los gráficos y que } \\
\text { una estupenda animación en Flash solamente cumple su objetivo si no } \\
\text { sustituye texto directo y claro que ayude a los motores y a los usuarios } \\
\text { a entender el sitio. En todo caso, cada vez más, Flash está } \\
\text { desaconsejado y se recomienda adoptar en su lugar soluciones basadas } \\
\text { en HTML5. }\end{array}$ \\
\hline
\end{tabular}




\begin{tabular}{|l|l|}
\hline $\begin{array}{l}\text { Presencia en } \\
\text { las redes y } \\
\text { usuararios de }\end{array}$ & $\begin{array}{l}\text { Las redes sociales y las señales de usuario procedentes de ellas son un } \\
\text { input imprescindible para el tráfico, y a la larga para el algoritmo de } \\
\text { posicionamiento de los buscadores. Los enlaces de entrada que } \\
\text { provienen de las redes sociales tienen cada vez más influencia, tanto en } \\
\text { el tráfico como en el posicionamiento. }\end{array}$ \\
$\begin{array}{l}\text { Publicar contenidos de calidad que no se promocionan a través de las } \\
\text { redes sociales es hacer las cosas a medias. Hasta que un contenido no } \\
\text { se "mueve" en las redes, se cita, se envían twits, se comenta, recibe "me } \\
\text { gusta", etc., es como si tuviera una existencia clandestina. }\end{array}$ \\
$\begin{array}{l}\text { Lo ideal es utilizar un CMS que facilite la difusión de los contenidos } \\
\text { mediante páginas dinámicas (independientes) con botones } \\
\text { incorporados que inviten a compartir los contenidos en las redes de } \\
\text { forma fácil (y automática), además de las acciones que pueden llevarse } \\
\text { a cabo de gestión de la comunidad. }\end{array}$ \\
\hline Tráfico \\
$\begin{array}{l}\text { El tráfico en el sitio web también influye en el posicionamiento, como } \\
\text { un pez que se muerde la cola. Las acciones de promoción fuera y dentro } \\
\text { de la web de la página siempre tienen sentido. }\end{array}$ \\
\hline
\end{tabular}

\subsection{Otras listas de factores}

Se dice que Google utiliza más de 200 factores para determinar el posicionamiento de una página. Lógicamente, algunos de estos factores tienen una gran importancia, y otros, por el contrario, un peso muy pequeño.

La cuestión es que últimamente han aparecido algunas listas de factores de posicionamiento SEO de bastante prestigio por estar elaboradas por empresas consideradas bastante solventes. Dos de los más importantes son los siguientes:

\section{MOZ}

https://moz.com/search-ranking-factors

\section{Searchmetrics}

http://www.searchmetrics.com/knowledge-base/ranking-factors/ 
Son listas muy detalladas, como puede verse y en ocasiones parece que nos producen el conocido efecto de "los árboles que no nos dejan ver el bosque", además son listas muy sensibles a cambios pequeños en los algoritmos de Google y suelen estar centradas en los índices de Google de Estados Unidos que no siempre es trasladable a otros países.

No obstante, no dejan de ser un elemento de estudio y de consideración para quienes deseen profundizar más en este tema, aunque sinceramente, creemos que quienes atiendan a la lista que nosotros hemos presentado en el cuadro anterior, no irán mal encaminados.

\section{Optimización de noticias}

A continuación, presentamos un procedimiento, basado en el Framework RCP, presentado en otros trabajos por el Grupo DigiDoc (Codina et al., 2016) para optimizar el SEO de las noticias individuales. Algunos de estos puntos pueden obligar a editar o re- escribir partes de la noticia. Debe procederse siempre a esta edición salvo si afecta a la calidad periodística. En caso de contradicción entre el imperativo SEO y el imperativo Periodístico, el SEO debe ceder.

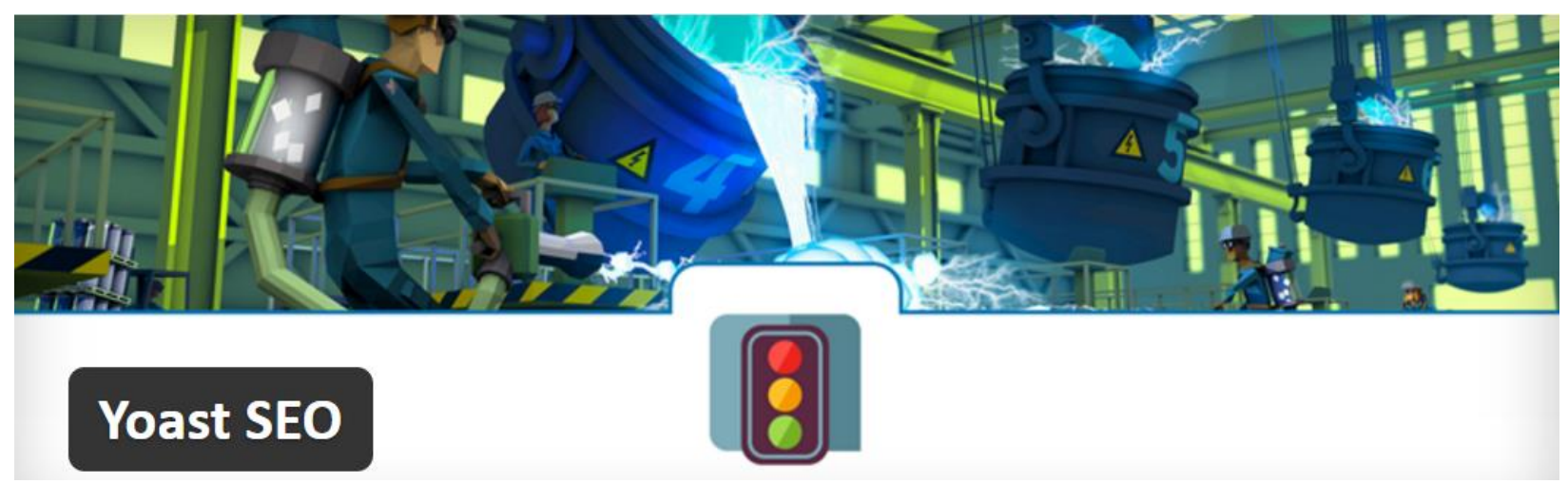

Figura 9. Yoast SEO es uno de los complementos (plugin) más utilizados por sitios gestionados con WordPress, que a su vez es uno de los CMS más utilizados por medios de comunicación.

El periodismo está al servicio de las personas, no de Google. Por ejemplo, como se verá enseguida, el punto de chequeo 1 propone una extensión mínima de 300 palabras, pero esto debe aplicarse cuando no vaya contra el género periodístico concreto.

En todo caso, y cuando no haya contradicción, los puntos a considerar son los siguientes:

1. Extensión. La entrada debe tener al menos $\mathbf{3 0 0}$ palabras, y mejor si supera esa cifra

2. Multimedia. Añada siempre algún componente multimedia, al menos una fotografía.

3. Palabra clave. Decida cuál es la palabra clave principal de su entrada. 
4. Distribución óptima de la palabra clave:

1. En el título principal o título periodístico (etiqueta h1)

2. En la URL de la entrada. Edite la URL si es necesario para evitar palabras vacías y limitar la extensión. Es preferible títulos cortos y fácilmente manejables.

3. En el título SEO, a través de la etiqueta <title>. Máximo 65 caracteres

4. En los metadatos con el atributo description de la etiqueta <meta>. Máximo 140 caracteres

5. En uno de los titulares del cuerpo de la noticia (etiqueta h2)

6. En el primer párrafo

7. En alguno(s) de los párrafos centrales

8. En alguno(s) de los párrafos finales

9. En una de las imágenes.

10. En alguno de los hiperenlaces externos a fuentes relacionadas

5. Énfasis. En alguna de las ocurrencias, la palabra clave debe estar marcada en negrita o cursiva

6. Navegación interna - Taxonomías. La noticias debe estar asignada al menos a una categoría y a una o más etiquetas.

7. Navegación interna - Noticias relacionadas. La noticia, a ser posible, debe estar enlada a noticias anteriores relacionadas por el contenido.

8. Apoyo semántico. Utilice sinónimos y términos relacionados con la palabra clave en el cuerpo y/o en los titulares de la entrada para apoyar la fortaleza de la palabra clave.

9. Credibilidad. Mencione entidades concretas en forma de nombre de personas, lugares o instituciones, y añada enlaces a las entidades si es el caso. Puede servir en este caso para cubrir el punto 10 de la distribución óptima.

10. Web social y contenido adaptativo. Asegúrese de configurar la entrada de modo que se publique en redes sociales, así como de disponer de botones de (re) difusión en redes sociales activados y configurados. En caso de disponer de la posibilidad con su CMS, considere si desea proponer títulos, descripciones e imágenes específicas para redes como Facebook y Twitter.

11. Programación. Programe la entrada, si es el caso, para que se publique en el momento óptimo según su consideración y naturaleza.

En los medios de comunicación que utilizan sistemas de CMS, como WordPress, para gestionar su sitio web y crear y publicar las noticias, es posible utilizar extensiones (plugins) como Yoast SEO o All in One SEO que ayudan de forma considerable a los redactores a chequear la mayoría de los puntos anteriores e incluso a automatizar al menos parte de los mismos. 


\section{Discusión y conclusiones}

Las oportunidades que Internet para una empresa de comunicación que ha determinado bien su cobertura temática y sabe desarrollar contenidos de interés para su público objetivo, son muchas. Además, puede desarrollar una campaña de posicionamiento como ya hemos señalado con un coste relativamente bajo.

El aspecto más importante del SEO actual es la creación de contenidos de calidad, y este es precisamente (o debería ser) el núcleo de la actividad de un cibermedio.

La buena noticia es que muchos sitios web (por ejemplo, los que están vinculados con instituciones del mundo de la cultura, muchos organismos del sector público, empresas editoriales, empresas del sector de la comunicación, etc.) ya tienen o ya producen estos contenidos de forma "natural", y dentro de estos sitios, los medios de comunicación destacan entre todos ellos. Después de todo, se supone que la creación de contenidos originales, con el uso de fuentes propias y desarrollados con criterios de calidad y bien orientados a su público es el núcleo del negocio de la prensa.

Y siguiendo con las buenas noticias, la compensación llegará en todos los casos cuando veamos que obtenemos un tráfico de usuarios realmente interesados en nuestro sitio, lo que siempre se traduce en clientes y oportunidades de monetización en diversos modelos de negocio, desde la publicidad hasta las suscripciones.

Por último, podemos señalar los siguientes puntos:

1. Las campañas de posicionamiento tienen su inicio en el estudio de las palabras y frases clave para las cuales deseamos optimizar nuestro sitio de cara a los motores de búsqueda, y en el caso de un cibermedios con años de funcionamiento, en el estudio de su perfil de palabras clave. Las herramientas de análisis SEO pueden indicarnos, concretamente, cuántas palabras clave de un sitio forman parte de las 10 o de las 100 primeras páginas de resultados de Google. En todo caso, el estudio y determinación de las palabras clave es un aspecto que, en el caso de los medios de comunicación en buena parte viene dado por su cobertura temática y las características de su público, pero que se beneficia del estudio de palabras clave. 
2. El contenido, amplio, original y enriquecido con componentes multimedia (fotos, gráficos, vídeos, diagramas, etc.) es la clave principal del posicionamiento. Los medios de comunicación, además, aportan el uso de fuentes propias y unas estrategias de desarrollo de formatos de alta calidad.

3. Aunque los componentes multimedia son importantes, nuestro sitio web debe tener siempre contenidos de texto acompañando al contenido multimedia: no sirven los gráficos o las animaciones en flash si no están tratados con metadatos y nombres de ficheros significativos.

4. Las taxonomías tienen un rol central en dos aspectos clave de un cibermedio: en la navegación interna del mismo y en la optimización del SEO de los contenidos de aquellas temáticas similares que un medio de comunicación no tiene más remedio que volver repetidamente.

5. La páginas, esto es, las noticias, de nuestro sitio debe ser optimizadas también a nivel de código fuente y metadatos para las palabras clave seleccionadas.

6. Buenos contenidos nos ayudan a obtener enlaces de entrada de terceros de forma relativamente natural, pero la actitud proactiva en la obtención de enlaces de entrada sigue siendo muy importante para el éxito en una campaña de posicionamiento.

7. Las actualizaciones son siempre un factor importante. Las actualizaciones, es decir, la provisión frecuente de nuevos contenidos refuerza este papel clave. En este sentido, el sitio de un medio de comunicación no debería tener especiales problemas. En todo caso, no se concibe un medio de comunicación que no actualice sus contenidos varias veces cada semana, y a ser posible, varias veces al día.

8. En el caso de un medio de comunicación, además, los contenidos, al menos en parte, deben ser originales. Esto no significa que deben ser exóticos, sino que deben ser de creación propia, con uso de fuentes y verificación y contrastación de datos e informaciones. Otra parte de los contenidos, ciertamente, será similar a la de otros cibermedios, ya que la cobertura de la actualidad es un imperativo. Incluso cuando el medio haga curación de contenidos, esta curación debe contener aportaciones del periodista: interpretación, análisis, crítica, comparación, etc. 
9. Los buenos contenidos, sin embargo, no sirven de nada si nuestra web presenta problemas técnicos que impiden el acceso o ponen barreras técnicas a los motores de búsqueda.

10. Igualmente, los buenos contenidos no sirven de nada, al menos a corto y medio plazo, si no adoptamos una política activa de posicionamiento basada en la web social y en una buena actividad de gestión de la comunidad.

\section{Bibliografía citada y consultada}

- Bailyn, E.; Bailyn, B. (2012). Ganar con Google. Madrid: Anaya.

- Codina, Lluís; Marcos, Mari Carmen (2005). “Posicionamiento web: conceptos Y herramientas". El profesional de la información, v. 14, n. 2, pp. 84-99.

- Codina, Lluís; Pedraza-Jiménez, Rafael (2011). "Tesauros y ontologías en sistemas de información documental". El Profesional de la Información. 2011; 20 (5): 555-63.

- Codina, Lluís; Pedraza-Jiménez, Rafael; Díaz-Noci, Javier; Rodríguez-Martínez, Ruth; Pérez-Montoro, Mario; Cavaller-Reyes, Víctor (2014). "Sistema Articulado de Análisis de Cibermedios (SAAC): Una propuesta sobre el qué y el cómo para estudiar medios de comunicación digitales". Hipertext.net, (12).

- Codina, Lluís; Iglesias García, Mar; Pedraza-Jiménez, Rafael; García Carretero, Lucía. (2016). Search engine optimization and online journalism: the SEO-WCP framework. Barcelona: UPF. Departamento de Comunicación. Serie Editorial DigiDoc.

- Enge, E. et al. (2012). The Art of SEO. Sebastopol, O’Reilly, 2012.

- Figueroa Encina, Patricio (2016). "Oportunidades y desafíos para cibermedios en el Ecosistema Móvil. Instant Articles de Facebook y los nuevos formatos móviles." Hipertext.net: Anuario Académico sobre Documentación Digital y Comunicación Interactiva [online], 2016,, Núm. 14 . http://raco.cat/index.php/Hipertext/article/view/310534 
- Figueroa Encina, Patricio (2017). "Facebook Journalism Project: la apuesta del gigante social en el mundo de las noticias". SEO Media Lab. Febrero 2017. https://seomedialab.com/facebook-journalism-project-la-apuesta-del-gigante-social-mundo-las-noticias/

- Fleischner, Mr. Michael H. (2011). SEO Made Simple: Strategies For Dominating The World's Largest Search Engine. Create Space Independent Publishing.

- Freixa, Pere; Soler-Adillon, Joan; Sora, Carles; Ribas, J. Ignasi (2014). “Aportaciones del découpage interactivo en la lectura y análisis de audiovisuales interactivos de los cibermedios". Hipertext.net, 2014

- García-Carretero, Lucía; Codina, Lluís; Pedraza-Jiménez, Rafael (2016). Indicadores para el Estudio de la Visibilidad y del Impacto de los Cibermedios en el Ecosistema Digital. Barcelona: UPF. Departamento de Comunicación. Serie Editorial DigiDoc.

- Gonzalo-Penela, Carlos. (2015). Posicionamiento web y dinámicas de información en motores de búsqueda: propuestas de análisis y estudio comparativo de visibilidad de contenidos digitales en el caso de procesos electorales. [Tesis doctoral] Barcelona: UPF, 2015. http://hdl.handle.net/10230/23621

- Gonzalo-Penela, Carlos; Codina, Lluís; Rovira, Cristòfol. (2015), "Recuperación de información centrada en el usuario y seo: categorización y determinación de las intenciones de búsqueda en la web". Index.comunicación. 5(3).

- Grappone, J.; Couzin, G. (2006). "Your one-month prep: Baseline and Keywords". Search engine optimization: an hour a day. Indianapolis: Sibex, 2006.

- Google (2016). Search Quality Rating Guidelines. https://static.googleusercontent.com/media/www.google.com/es//insidesearch/howse archworks/assets/searchqualityevaluatorguidelines.pdf

- Kent, P. (2006). "Building search-engine-friendly sites". Search engine optimization for dummies. Indianapolis: Wiley.

- Maciá, Fernando (2011). Técnicas avanzadas de posicionamiento en buscadores. Anaya Multimedia.

- Iglesias-García, Mar; Fernández Poyatos, M. D. (2011). “Ciberperiodismo: definiciones, desarrollo y tipología". Bilbao: III Congreso Internacional de Ciberperiodismo y Web 2.0. 
- Iglesias-García, Mar; Codina, Lluís (2106). “Los cibermedios y la importancia estratégica del posicionamiento en buscadores (SEO)". Opción, 2016

- Pedraza-Jiménez, Rafael; Codina, Lluís; Guallar, Javier (coords.) (2016). Calidad en sitios web. Método de análisis general, e-commerce, imágenes, hemerotecas y turismo. Colección EPI Scholar. Barcelona: Editorial UOC, 2016

- Pedraza-Jiménez, Rafael, Blanco, Saul; Codina, Lluís; Cavaller, Víctor (2013). Diseño conceptual y especificación de requerimientos para el desarrollo y rediseño de sitios web. El profesional de la información, 22(1), 74-79.

- Pérez-Montoro, Mario; Codina, Lluís (2017). Navigation Design and SEO for ContentIntensive Websites: A Guide for an Efficient Digital Communication. Oxford: Chandos Publishing -Elsevier

- Rodríguez-Martínez, Ruth; Codina, Lluís; Pedraza-Jiménez, Rafael (2010). Cibermedios y web 2.0: modelo de análisis y resultados de aplicación. El profesional de la información, 19(1), 35-44.

- Rovira, Cristòfol; Fernández-Cavia, José; Pedraza-Jiménez, Rafael; Huertas, A. (2010). "Posicionamiento en buscadores de las webs oficiales de capitales de provincia españolas". El profesional de la información, 19(3), 277-283.

- Rovira, Cristòfol; Codina, Lluís; Marcos, Mari-Carmen (2009). "Cómo contratar un servicio de posicionamiento Web". El Profesional de la información; 18(2): 229-236.

- Vàllez, Mari; Rovira, Cristòfol; Codina, Lluís; Pedraza-Jiménez, Rafael (2010). "Procedures for extracting keywords from web pages, based on search engine optimization". Hipertext.net, 8.

- Vàllez, Mari (2011). "Keyword Research: métodos y herramientas para identificar palabras clave". BiD: Textos Universitaris de Biblioteconomia i Documentació, 27.

- Vàllez, Mari; Pedraza-Jiménez, Rafael; Codina, Lluís; Blanco, S.; Rovira, Cristòfol. (2015). "Updating controlled vocabularies by analysing query logs". Online Information Review, 39(7), 870-884. 